\title{
CIBERCULTURA E EDUCAÇÃO: uma revisão sistemática da literatura
}

\author{
Sandra Cristina Morais de Souza
}

\section{Resumo}

Este estudo teve o objetivo de revisar a produção científica acerca da cibercultura e da educação. Realizou-se uma revisão sistemática da literatura, com artigos pesquisados no Portal da CAPES (periódicos), a partir dos descritores 'cibercultura', 'cibercultura' e 'educação'. O critério de inclusão foram artigos nacionais dos anos de 2010 a 2019 e oriundos de estudos desenvolvidos no Brasil. Os critérios de exclusão foram dissertações, teses e demais textos, pois nosso foco de estudo deteve-se apenas a artigos científicos. Por meio desse processo, a amostra final foi constituída de 28 artigos. A escolha dos artigos se deu em relação ao seu título e posterior leitura dos resumos e, em seguida, na elaboração de um quadro dos dados coletados com informações de cada pesquisa, a saber: título, ano de publicação, autores, revista/periódico. A análise do estudo foi feita qualitativamente. As publicações revisadas descrevem as relações entre a cibercultura e o processo educativo, com destaque para conceitos como: mídia, ciberespaço, comunidade virtual, novas tecnologias, hipertexto, cultura, cultura digital, entre outros. Os estudos ressaltam que o crescimento do conceito de cibercultura está atrelado ao conceito de ciberespaço, que apresenta uma nova dimensão social, resultante de um movimento global em que predomina a conexão em tempo real. O ciberespaço é um espaço de aprendizagem, onde o uso de ferramentas midiáticas se apresenta como um recurso a ser utilizado pelo docente no processo de ensino e aprendizagem.

Palavras-chave: cultura; cibercultura; cibercultura e educação; ciberespaço.

\section{CYBERCULTURE AND EDUCATION: a systematic review of the literature}

\begin{abstract}
This study aimed to review the scientific production about cyberculture and education. A systematic literature review was carried out, with articles searched on the CAPES Portal (periodicals), using the descriptors 'cyberculture', 'cyberculture' and 'education'. The inclusion criteria were national articles from the years 2010 to 2019 and from studies carried out in Brazil. The exclusion criteria were dissertations, theses and other texts, as our study focus was limited to scientific articles. Through this process, the final sample consisted of 28 articles. The choice of articles was made in relation to their title and subsequent reading of the abstracts and, then, in the preparation of a table of collected data with information from each research, namely: title, year of publication, authors, journal/journal. The study analysis was carried out qualitatively. The reviewed publications describe the relationship between cyberculture and the educational process, highlighting concepts such as: media, cyberspace, virtual community, new technologies, hypertext, culture, digital culture, among others. The studies highlight that the growth of the cyberculture concept is linked to the concept of cyberspace, which presents a new social dimension, resulting from a global movement in which real-time connection predominates. Cyberspace is a learning space, where the use of media tools is presented as a resource to be used by the teacher in the teaching and learning process.
\end{abstract}


Keywords: culture; cyberculture and education; cyberspace.

\section{CIBERCULTURA Y EDUCACION: una revisión sistemática de la literature}

\section{Resumen}

Este estudio tuvo como objetivo revisar la producción científica sobre cibercultura y educación. Se realizó una revisión sistemática de la literatura, con búsqueda de artículos en el Portal CAPES (publicaciones periódicas), utilizando los descriptores 'cibercultura', 'cibercultura' y 'educación'. Los criterios de inclusión fueron artículos nacionales de los años 2010 a 2019 y de estudios realizados en Brasil. Los criterios de exclusión fueron disertaciones, tesis y otros textos, ya que nuestro enfoque de estudio se limitó a artículos científicos. Mediante este proceso, la muestra final constó de 28 artículos. La elección de los artículos se realizó en función de su título y posterior lectura de los resúmenes y, luego, en la elaboración de una tabla de datos recolectados con información de cada investigación, a saber: título, año de publicación, autores, revista / revista. El análisis del estudio se realizó de forma cualitativa. Las publicaciones revisadas describen la relación entre la cibercultura y el proceso educativo, destacando conceptos como: medios, ciberespacio, comunidad virtual, nuevas tecnologías, hipertexto, cultura, cultura digital, entre otros. Los estudios destacan que el crecimiento del concepto de cibercultura está ligado al concepto de ciberespacio, que presenta una nueva dimensión social, resultado de un movimiento global en el que predomina la conexión en tiempo real. El ciberespacio es un espacio de aprendizaje, donde el uso de herramientas mediáticas se presenta como un recurso para ser utilizado por el docente en el proceso de enseñanza y aprendizaje.

Palabras clave: cultura; cibercultura y educación; ciberespacio.

\section{INTRODUÇÃO}

A palavra mudança sempre acompanhou a história da humanidade. Nas últimas décadas, ganhou mais impacto, agilidade e fluidez. Avançamos significativamente em várias direções, mas, com certeza, a revolução tecnológica, mais precisamente a Internet, revolucionou a sociedade. A conectividade abriu espaços antes impensáveis e saímos de um saber individual para um saber coletivo, construído e reconstruído cotidianamente.

Essas mudanças impactaram e ainda impactam a realidade, transformando contextos e abrindo espaços para novos nexos, sejam eles estruturais, sociais, objetivos ou subjetivos. Existem duas forças que impulsionaram essas mudanças: a evolução da ciência e as novas tecnologias de produção. Ao olhar as transformações decorrentes dessas forças, podemos visualizar as mudanças do poderio econômico, as alterações nos modelos de produção, a circulação e a acumulação de bens e de serviços e o processo de globalização, que eliminou as barreiras do mercado.

Considerando o panorama exposto, o objetivo deste estudo foi de revisar a produção científica sobre cibercultura e educação publicada em artigos nacionais entre 2010 e 2019. Esperamos que este trabalho possa contribuir com as investigações que vêm sendo realizadas acerca desse tema. 


\section{FUNDAMENTAÇÃO TEÓRICA}

No final do Século XVIII e no princípio do seguinte, o termo germânico Kultur era utilizado para simbolizar todos os aspectos espirituais de uma comunidade, enquanto a palavra francesa civilization referia-se, principalmente, às realizações materiais de um povo. Ambos os termos foram sintetizados por Edward Tylor (1832-1917), no vocábulo inglês culture, que, "[....] tomado em seu amplo sentido etnográfico, é todo complexo que inclui conhecimentos, crenças, arte, moral, leis, costumes ou qualquer outra capacidade ou hábitos adquiridos pelo homem como membro de uma sociedade" (TYLOR, 1871, p. 1 apud LARAIA, 2007, p. 25).

Para Thompson (1995), embora a compreensão de cultura recaia no olhar antropológico, não é possível destituí-la da realidade, descontextualizando-a da materialidade de seu processo histórico. Nesse sentido, a cultura só pode ser considerada no contexto amplo do desenvolvimento histórico, atrelada ao conceito de sociedade e de economia. Ao atar a compreensão de cultura ao conceito de sociedade e de economia, podemos compreender a cultura como algo que se movimenta, que evolui, um processo em constante mudança, cujos sentidos e valores se modificam conforme cada período histórico.

Para ampliar o debate a respeito da relação entre cibercultura e educação, precisamos discutir sobre alguns termos que acompanham esse debate. Pierre Levy, considerado um pioneiro na pesquisa sobre ciberespaço, compreende o ciberespaço como um momento decisivo de unificação da humanidade. Saímos de uma escala local e regional para uma global. Nesse contexto, o ciberespaço seria o elemento unificador, em que haveria o contato de bilhões de cérebros, constituindo o que o autor chama de hipercórtex, ou seja, um grande cérebro, onde se centraria o arquivo de toda a produção e memória humana (LEVY 2001).

Segundo Levy (1999), a cibercultura é um processo de mutação de formas de trabalhar, de se relacionar e de se sociabilizar, realizada a partir da existência do ciberespaço e de suas características novas. Para Lemos (2008), a cultura contemporânea, associada às tecnologias digitais criou uma nova relação entre a técnica e a vida social, denominada de cibercultura.

Ainda, segundo Levy (2009, p. 16), a cibercultura pode ser considera como um "[...]conjunto de técnicas (Materiais e Intelectuais), de práticas, de atitudes, de modos de pensamento e de valores que se desenvolvem juntamente como crescimento do ciberespaço".

A partir da leitura que fizemos dos autores e da definição de cibercultura, podemos compreendê-la não apenas como uma cultura produzida em termos de ciberespaço, mas também como uma dimensão da cultura contemporânea, que encontra no ciberespaço o principal lugar para se manifestar.

\section{PROCEDIMENTO METODOLÓGICO}

Trata-se de um estudo de revisão sistemática da literatura, que é adequado para se buscar um consenso sobre um tema específico e sintetizar o conhecimento de dada área por meio da formulação de uma pergunta, da identificação, da seleção e da avaliação crítica de estudos científicos contidos em bases de dados eletrônicas. Segundo Sampaio e Mancini 
(2007), a revisão sistemática se apresenta como uma forma de pesquisa que utiliza como fonte de dados a literatura vigente sobre o tema.

A pergunta de pesquisa foi: Como se encontra as publicações de artigos científicos já produzido no Brasil sobre cibercultura e educação? A busca de artigos foi realizada no Portal da CAPES (periódicos), sua escolha deve-se ao fato de possibilitar o acesso a produção cientifica mundial, com mais de 50.000 títulos de periódicos nacionais e internacionais, incluindo teses, patentes, trabalhos publicados em eventos, artigos, entre outros. Principais bases de dados hospedadas no Portal de Periódicos CAPES: ACM Digital Library; BioMed Central Journals; Cambridge Core; Clinics Collection (Elsevier); JAMA Network (AMA); Journal Citation Reports (JCR); Latindex: Portal de Portales; Library, Information Science \& Technology Abstrac; Nature; OECD iLibrary; Oxford Journals (Oxford University Press); Proceedings of the National Academy of Sciences (PNAS); Science Direct; Science (AAAS);Scopus; SpringerLink; Web of Science; Wiley Online Library; IOP Latinoamérica (Institute of Physics - IOP); Taylor \& Francis Online

$\mathrm{Na}$ pesquisa foram utilizados os seguintes descritores: cibercultura e cibercultura e educação. A escolha dos artigos deu-se a partir do seu título e posterior leitura dos resumos das publicações selecionadas, com o objetivo de refinar a amostra por meio de critérios de inclusão e exclusão. Foram incluídos artigos originais publicados entre 2010 e 2019 e oriundos de estudos desenvolvidos no Brasil.

Os critérios de exclusão foram dissertações, teses e demais textos, pois nosso foco de estudo deteve-se apenas a artigos científicos. Por meio desse processo, a amostra final foi constituída de 28 artigos. A análise dos artigos consistiu na leitura dos resumos e, em seguida, na elaboração de um quadro dos dados coletados com informações de cada pesquisa, a saber: título, ano de publicação, autores e revista/periódico. Também foi feita uma análise temática de conteúdo por meio da leitura e da releitura dos resumos, a fim de identificar o objetivo do estudo, a metodologia utilizada e os resultados.

\section{RESULTADOS E DISCUSSÃO}

$\mathrm{Na}$ busca foram encontrados 50 (cinquenta) artigos, destes selecionamos 28 (vinte e oito), a saber: 01 (um) artigo publicado no ano de 2010; 03 (três) artigos em 2012; 03 (três) artigos em 2013; 02 (dois) artigos em 2014; 01 (um) artigo em 2015; 03 (três) artigos em 2016; 02 dois artigos em 2017; 10 (dez) artigos em 2018, e 03 (três) artigos em de 2019. Os artigos excluídos não se adequaram ao critério de inclusão desta pesquisa, devido a leitura dos resumos que não se faziam pertinente com nosso objeto de estudo.

Em relação ao periódico com o maior número de publicações, destacou-se a Revista Espaço Acadêmico, que publicou três artigos sobre o tema. Convém salientar que os demais artigos da amostra são oriundos de revistas multidisciplinares, que abrangem publicações que ressaltam a cultura, a tecnologia, a filosofia, a comunicação, entre outros.

No que se refere à quantidade de autores, foram encontrados artigos publicados por dois ou três autores, a maioria da área de Educação, além de Ciência da Computação, Filosofia e Linguística. Quanto à titulação acadêmica, os autores eram, majoritariamente, doutores, mestres, doutorandos, mestrandos e especialistas. 
DOI: $10.12957 /$ teias.2022.55310

Tabela 1 - Distribuição dos artigos pesquisados de acordo com o título, o ano, os autores e a revista/periódico

\begin{tabular}{|c|c|c|c|}
\hline Título & Ano & Autor/es & Revista/periódico \\
\hline $\begin{array}{l}\text { Os desafios da educação: a cibercultura na } \\
\text { educação e à docência online }\end{array}$ & 2010 & $\begin{array}{l}\text { Nelma Vilaça Paes } \\
\text { Barreto }\end{array}$ & Vértices \\
\hline $\begin{array}{l}\text { Cibercultura e Educação: algumas reflexões sobre } \\
\text { processos educativos na sociedade tecnológica } \\
\text { contemporânea }\end{array}$ & 2012 & $\begin{array}{l}\text { Vitor Malaggi } \\
\text { Karina Marcon }\end{array}$ & $\begin{array}{l}\text { Revista Espaço } \\
\text { Acadêmico }\end{array}$ \\
\hline $\begin{array}{l}\text { A utilização da informática na educação: um olhar } \\
\text { através da cibercultura e do pensamento pós- } \\
\text { moderno }\end{array}$ & 2012 & Vitor Malaggi & $\begin{array}{l}\text { Revista Espaço } \\
\text { Acadêmico }\end{array}$ \\
\hline A educação em um contexto de cibercultura & 2012 & $\begin{array}{l}\text { Adriano Canabarro } \\
\text { Teixeira }\end{array}$ & $\begin{array}{l}\text { Revista Espaço } \\
\text { Acadêmico }\end{array}$ \\
\hline $\begin{array}{l}\text { Territórios digitais: dilemas e reflexões sobre } \\
\text { práticas de adolescentes na cibercultura }\end{array}$ & 2013 & $\begin{array}{l}\text { Fátima Ivone de } \\
\text { Oliveira Ferreira } \\
\text { Lúcia Regina Goulart } \\
\text { Vilarinho }\end{array}$ & Interacções \\
\hline $\begin{array}{l}\text { Educação e cibercultura: aprendizagem ubíqua no } \\
\text { currículo da disciplina Didática }\end{array}$ & 2013 & $\begin{array}{l}\text { Edméa Santos } \\
\text { Aline Weber }\end{array}$ & $\begin{array}{l}\text { Revista Diálogo } \\
\text { Educacional }\end{array}$ \\
\hline $\begin{array}{l}\text { Indústria cultural e cibercultura - aproximações e } \\
\text { distanciamentos de conceitos e práticas na } \\
\text { contemporaneidade }\end{array}$ & 2013 & $\begin{array}{l}\text { Marcus Alexandre de } \\
\text { Pádua Cavalcanti }\end{array}$ & $\begin{array}{l}\text { Periferia - educação, } \\
\text { Cultura \& Comunicação }\end{array}$ \\
\hline $\begin{array}{l}\text { Educação na cibercultura: as tecnologias da } \\
\text { inteligência e a práxis educativa }\end{array}$ & 2014 & $\begin{array}{l}\text { Renato Kraide Soffner } \\
\text { Deise Becker Kirsch }\end{array}$ & Revista Intersaberes \\
\hline $\begin{array}{l}\text { Flexibilidade educacional na cibercultura: } \\
\text { analisando espaços, tempos e currículo em } \\
\text { produções científicas da área educacional }\end{array}$ & 2014 & Daniel Mill & RIED \\
\hline
\end{tabular}


DOI: $10.12957 /$ teias.2022.55310

Educação como terreno de epifania da cibercultura: leituras e cenários
2015

Ro

|

Mediação docente online para colaboração: notas de uma pesquisa-formação na cibercultura

Virtualização e sociedade digital: reflexões acerca das modificações cognitivas e identitárias nos sujeitos imersivos

Processos formativos de uma mídia ninja e as novas narrativas do ativismo no contexto da cibercultura

cibercultura

Conversações fluidas na cibercultura

Comunicação, educação e tecnologia: espaços colorativos digitais de ensino e aprendizagem

\section{Freitas}

Vivianne Margareth

Chaves Pereira Reis

Josiane Santos Brant

Rocha

Edméa Oliveira Santos

Felipe Silva Ponte

Carvalho

Mariano Pimentel

2016

Martha Kaschny

Conjectura: Filos. Educ.

Borges

Sandro de Oliveira

2016

T. S. Paz

HOLOS

C.O. B. Sales

N.R. Santos

S. Junqueira

2017

Alex Teixeira Primo

Revista Famecos

Vanessa Valiati

Mídia, cultura e

Ludmila Lupinacci

tecnologia

Laura Barros

2017

Kamil Giglio

Revista Intersaberes 
DOI: $10.12957 /$ teias.2022.55310

\begin{tabular}{|c|c|c|c|}
\hline $\begin{array}{l}\text { Contra-educação e cibercultura: uma interlocução } \\
\text { possível à luz da cidadania global }\end{array}$ & 2018 & $\begin{array}{l}\text { Alexandre Guilherme } \\
\text { Lucia Maria Martins } \\
\text { Giraffa } \\
\text { Cristina Martins }\end{array}$ & Foro de Educación \\
\hline Cibervídeos e multiletramentos na educaçao online & 2018 & $\begin{array}{l}\text { Edméa Santos } \\
\text { Vivian Martins }\end{array}$ & Revista Observatório \\
\hline $\begin{array}{l}\text { Cyberativismo e Educação: o conceito de raça e } \\
\text { racismo na cibercultura }\end{array}$ & 2018 & $\begin{array}{l}\text { Luzineide Miranda } \\
\text { Borges } \\
\text { Mille Caroline } \\
\text { Rodrigues Fernandes }\end{array}$ & $\begin{array}{l}\text { Revista Espaço } \\
\text { Acadêmico }\end{array}$ \\
\hline $\begin{array}{l}\text { Biopolíticas de currículo: notas de uma pesquisa- } \\
\text { formação na cibercultura }\end{array}$ & 2018 & $\begin{array}{l}\text { Mirian Maia do Amaral } \\
\text { Edméa Oliveira dos } \\
\text { Santos }\end{array}$ & $\begin{array}{l}\text { Acta Scientiarum. } \\
\text { Education }\end{array}$ \\
\hline $\begin{array}{l}\text { Linguagem emocional na prática docente online: } \\
\text { implicações educacionais cotidianas }\end{array}$ & 2018 & $\begin{array}{l}\text { Caroline Costa Nunes } \\
\text { Lima } \\
\text { Felipe Silva Ponte } \\
\text { Carvalho } \\
\text { Dilton Ribeiro Couto } \\
\text { Júnior }\end{array}$ & Rev. Inter. Educ. Sup. \\
\hline $\begin{array}{l}\text { Ciberautorcidadão: contribuição para pensarfazer a } \\
\text { formação docente e discente na cibercultura }\end{array}$ & 2018 & $\begin{array}{l}\text { Mayra Rodrigues } \\
\text { Fernandes Ribeiro } \\
\text { Edméa Oliveira dos } \\
\text { Santos }\end{array}$ & Revista e-Curriculum \\
\hline $\begin{array}{l}\text { Formação continuada de professores em } \\
\text { tecnologia: a "ousadia" na dialogicidade entre a } \\
\text { universidade e a escola }\end{array}$ & 2018 & $\begin{array}{l}\text { Gláucia da Silva Brito } \\
\text { Ariana Chagas Knoll } \\
\text { Michele Simonian }\end{array}$ & Revista e-Curriculum \\
\hline $\begin{array}{l}\text { Entre filhos e órfãos da cibercultura: revisitando a } \\
\text { noção de nativos digitais }\end{array}$ & 2018 & Gilson Cruz Júnior & Revista Observatório \\
\hline
\end{tabular}


DOI: $10.12957 /$ teias.2022.55310

\begin{tabular}{|c|c|c|c|}
\hline $\begin{array}{l}\text { O professor e a autoria em tempos de cibercultura: } \\
\text { a rede da criação dos atos de currículo }\end{array}$ & 2018 & $\begin{array}{l}\text { Maristela Midlej Silva } \\
\text { de Araújo Veloso } \\
\text { Maria Helena Silveira } \\
\text { Bonilla }\end{array}$ & $\begin{array}{l}\text { Revista Brasileira de } \\
\text { Educação }\end{array}$ \\
\hline $\begin{array}{l}\text { Hibridações da cultura acadêmica com a } \\
\text { cibercultura: análise das práticas acadêmicas no } \\
\text { ambiente virtual de aprendizagem moodle }\end{array}$ & 2018 & $\begin{array}{l}\text { Lebiam Tamar Gomes } \\
\text { Silva } \\
\text { Irinalda da Silva } \\
\text { Bezerra }\end{array}$ & $\begin{array}{l}\text { Edur - Educação em } \\
\text { Revista }\end{array}$ \\
\hline $\begin{array}{l}\text { Memes de redes sociais digitais enquanto objetos } \\
\text { de aprendizagem na Cibercultura: da viralização à } \\
\text { educação }\end{array}$ & 2019 & $\begin{array}{l}\text { Kaio Eduardo de Jesus } \\
\text { Oliveira Cristiane de } \\
\text { Magalhães Porto } \\
\text { André Luiz Alves }\end{array}$ & $\begin{array}{l}\text { Acta Scientiarum. } \\
\text { Education }\end{array}$ \\
\hline $\begin{array}{l}\text { Os desafios da Educação no Campo em tempos } \\
\text { de Cibercultura }\end{array}$ & 2019 & $\begin{array}{l}\text { Kety da Costa Maciell } \\
\text { Paula Fernanda } \\
\text { Rodrigues Brum } \\
\text { Maria Silvana Gritti }\end{array}$ & $\begin{array}{l}\text { RELACult - Revista } \\
\text { Latino-americana de } \\
\text { Estudos em Cultura e } \\
\text { Sociedade }\end{array}$ \\
\hline $\begin{array}{l}\text { Interatividade, m-learning e apropriações das mídias } \\
\text { digitais para a inovação da educação superior }\end{array}$ & 2019 & $\begin{array}{l}\text { Davi de Menezes } \\
\text { Rebouças } \\
\text { Luana Ellen de Sales } \\
\text { Inocêncio } \\
\text { Letícia Adriana } \\
\text { Ferreira Pires dos } \\
\text { Santos }\end{array}$ & $\begin{array}{l}\text { Revista Educação e } \\
\text { Cultura Contemporânea }\end{array}$ \\
\hline
\end{tabular}

Fonte: Portal CAPES (2020)

$\mathrm{Na}$ busca pelas expressões cibercultura, cibercultura e educação, destacamos os objetivos de cada estudo a partir do olhar dos seus autores.

Barreto (2010) desenvolveu um trabalho sobre os conceitos de cibercultura, interatividade, ambientes virtuais de aprendizagem e educação a distância. O artigo de Malaggi e Marcon (2012) teve o objetivo de argumentar sobre as necessidades de ressignificar os processos educativos que emergem do contexto da sociedade contemporânea, configurada por uma nítida inter-relação entre cultura e tecnologias de caráter digital. 
O trabalho de Guilherme, Giraffa e Martins (2018) teve como objetivo discutir sobre as políticas educacionais das organizações internacionais, especialmente as relativas à cidadania global e suas implicações para a cibercultura/ciberespaço. Santos e Weber (2013), a partir do referencial teórico de Santos (2005), discutiram sobre as possibilidades de práticas pedagógicas para uma aprendizagem ubíqua, levando em consideração uma abordagem multirreferencial do currículo.

Santos e Martins (2018) apresentaram os resultados de um estudo exploratório, em que desenvolveram uma oficina de produção de cibervídeos na graduação em Pedagogia da Universidade do Estado do Rio. O estudo de Borges e de Fernandes (2018) buscou compreender quais são os conceitos de raça e de racismo que são compartilhados nas mídias sociais digitais e como esse espaço pode contribuir para um debate crítico e para fortalecer a educação antirracista.

Amaral e Santos (2018), em seu estudo, teceram considerações a respeito das contribuições de Michel Foucault para a Educação e o papel da Biopolítica e suas interrelações com o currículo nos cotidianos escolares. Oliveira, Porto e Alves (2019) fizeram um estudo sobre o potencial dos memes de redes sociais digitais como objetos de aprendizagem, autoria visual e produção colaborativa na Cibercultura.

Malaggi (2012) trouxe uma reflexão sobre as implicações filosóficas e sociais no contexto de utilização da Informática na Educação. Em seu artigo, Lima, Carvalho e Júnior (2018) se propuseram a investigar as implicações teórico-práticas da linguagem emocional na docência online.

Teixeira (2012) apresentou, em seu estudo, a ideia de que as tecnologias afetam diretamente a forma como nos comunicamos e aprendemos e que a cibercultura, marcada pelas tecnologias da inteligência, autoriza o estabelecimento de processos educativos mais ricos, criativos e inovadores. O artigo de Ribeiro e de Santos (2018), inserido no contexto da pesquisa-formação, teve o propósito de apresentar as tessituras epistemológicas e metodológicas na educação presencial e online na docência do ensino superior que, engendradas de sentidos e em ato, possibilitaram construir a noção de ciberautorcidadão.

Brito, Knoll e Simonian (2017) apresentam os resultados de uma experiência do Grupo de Estudo e Pesquisa Professor, Escola e Tecnologias Educacionais (Geppete), ao planejar, desenvolver e avaliar a formação 'Tecnologias e Educação na Cibercultura', o qual é integrante do projeto de formação continuada de professores - EduPesquisa.

Maciel, Brum e Gritti (2019) apresentaram o resultado de uma pesquisa realizada em uma escola municipal localizada em um Assentamento Rural da Reforma Agrária, no município de Pedras Altas - Rio Grande do Sul. O estudo foi realizado com alunos do $9^{\circ}$ ano do Ensino Fundamental.

O artigo de Primo et.al. (2017) visou estudar como o amplo leque de serviços de comunicação on-line participa da criação e da manutenção de relações interpessoais na contemporaneidade. $\mathrm{O}$ trabalho investiga os usos de diferentes plataformas digitais vem transformando as práticas de sociabilidade e as conversações no contexto da cibercultura, a partir da articulação de perspectivas teóricas e empíricas sobre esses temas.

Santos, Carvalho e Pimentel (2016) apresentam os dados de uma pesquisa-formação na cibercultura sobre a mediação docente com os cursistas da disciplina Informática na Educação, do Curso de Licenciatura em Pedagogia a Distância da UERJ/CEDERJ/UAB. 
Cruz Júnior (2018) buscou problematizar a noção de nativos digitais e o entendimento sociocognitivo dos jovens e das crianças e recorreu ao diálogo com a comunicação ubíqua e as culturas globais. Giglio (2017) visou identificar e refletir sobre o uso geral de tecnologias de informação e comunicação (TIC) no âmbito educacional.

Soffner e Kirsch (2014) fizeram um estudo com o objetivo de estudar a gestão da práxis educativa no contexto da cibercultura com o emprego dos recursos tecnológicos disponíveis para os processos de ensino e aprendizagem. Mill (2014) analisou os princípios da flexibilidade na educação e suas implicações na qualidade do ensino e da aprendizagem na Educação a Distância (EaD).

Veloso e Bonilla (2018) desenvolveram um trabalho com a finalidade de destacar a autoria docente na criação de atos de currículo condizentes com o contexto da cibercultura no cotidiano escolar. O estudo de Borges e de Oliveira (2016) teve o objetivo de refletir sobre as modificações cognitivas e identitárias nos/dos sujeitos da sociedade digital - denominados aqui de sujeitos imersivos, no sentido proposto por Santaella.

O trabalho de Paz et al (2016) objetivou compreender como se estruturam os processos formativos de um integrante do Mídia NINJA $(\mathrm{MN})$ e suas relações com o ativismo no contexto da cibercultura. Silva e Bezerra (2018) apresentam os resultados de uma pesquisa de iniciação científica (PIBIC) sobre a cultura acadêmica e o processo de hibridação com a cibercultura. O estudo teve o objetivo geral de verificar de que maneira as mediações entre os aprendentes e as tecnologias intelectuais digitais favorecem ou restringem a ressignificação da cultura acadêmica.

Em seu artigo (2013), Cavalcanti propõe uma reflexão sobre as relações e os processos de comunicação promovidos pelas redes digitais e os meios de comunicação de massas, no sentido de perceber, na contemporaneidade, como ambos se integram e se complementam em suas práticas. Rebouças, Inocêncio e Santos (2019) apresentam um olhar privilegiado sobre a utilização dessas novas mídias para um processo de ensino-aprendizagem inovador e dinâmico voltado para a validade empírica.

Santos et. al. (2015) desenvolveram uma pesquisa sobre a processão da cibercultura e seu entrecruzamento com a educação e apontaram cenários e possibilidades em um tempo de transformações.

Ferreira e Vilarinho (2013) compreendem o ciberespaço como uma extensão da própria vida do adolescente, a qual ultrapassa a separação entre o virtual e o real e, ao mesmo tempo, defende a apropriação crítica e criativa das redes sociais on line.

Quanto aos aspectos metodológicos, foi empregada a abordagem qualitativa. Em relação ao tipo de estudo, são majoritariamente bibliográficos, exploratórios e descritivos. É importante salientar que os delineamentos metodológicos dos estudos são coerentes com os objetivos traçados, embora seja perceptível que as pesquisas de caráter bibliográfico foram predominantes, o que demonstra uma análise da produção do conhecimento acerca da temática.

\section{CONSIDERAÇÕES FINAIS}

Os estudos ressaltam que o crescimento do conceito de cibercultura está atrelado ao conceito de ciberespaço, que apresenta uma nova dimensão social, resultante de um 
movimento global em que predomina a conexão em tempo real. O ciberespaço é um espaço de aprendizagem, onde o uso de ferramentas midiáticas se apresenta como um recurso a ser utilizado pelo docente no processo de ensino e aprendizagem.

Os estudos sobre cibercultura e educação são sobremaneira interessantes, desafiadores e instigantes. Com a revisão sistemática da literatura, foi possível transitar por várias perspectivas de estudos e as preocupações que os autores tiveram ao abordar o tema. Os conceitos de cibercultura e de ciberespaço nortearam os estudos e abriram um leque na perspectiva de ressignificar os processos educativos em uma sociedade cada vez mais digital.

Vale refletir, também, sobre as barreiras encontradas nas metodologias que cercam a educação on-line. Vale destacar, ainda, os estudos que priorizaram a questão do racismo nas mídias sociais, como um fator que merece atenção e cuidado, além do uso indevido dos recursos digitais. Fomos agraciados com a leitura dos estudos que contemplaram os elementos da subjetividade humana, como a identidade dos sujeitos na sociedade digital. Nessa mesma direção, discutimos sobre os adolescentes na sociedade virtual e o ciberespaço como uma extensão do seu corpo.

À guisa de conclusão, somos convidados a deixar aberta a perspectiva de novos estudos sobre o tema abordado. As leituras feitas nos possibilitaram perceber que as mudanças no conceito de cultura são díspares e, às vezes, contraditórias, porque envolvem posicionamentos, crenças, concepções e valores que se modificam no contexto histórico e temporal. Entretanto, mesmo em meio ao turbilhão de informações e de mudanças na sociedade em rede, convém perceber as contribuições do ciberespaço na educação.

\section{REFERÊNCIAS}

AMARAL, Mirian Maia do; SANTOS, Edméa Oliveira dos. Biopolíticas de currículo: notas de uma pesquisa-formação na cibercultura. Acta Scientiarum. Education, v. 40(2), e36086, 2018.

BARRETO, Nelma Vilaça Paes. Os desafios da educação: a cibercultura na educação e a docência online. Vértices. Campos dos Goytacazes/RJ.v. 12, n. 3, p. 149-164, set./dez. 2010. BORGES, Martha Kaschny Borges; OLIVEIRA, Sandro de. Virtualização e sociedade digital: reflexões acerca das modificações cognitivas e identitárias nos sujeitos imersivos. Conjectura: Filos. Educ., Caxias do Sul, v. 21, n. 2, p. 420-440, maio/ago. 2016.

BORGES Luzineide Miranda; FERNANDES, Mille Caroline Rodrigues. Cyberativismo e Educação: o conceito de raça e racismo na cibercultura. Revista Espaço Acadêmico. Caxias do Sul, n. 207. ago. 2018. Mensal.

BRITO, Gláucia da Silva; KNOLL, Ariana Chagas; SIMONIAN, Michele. Formação continuada de professores em tecnologia: a "ousadia" na dialogicidade entre a universidade e a escola. Revista e-Curriculum. v.15, n.01, p. 221 - 248 jan./mar.2017.

CAVALCANTI, Marcus Alexandre de Pádua. Indústria cultural e cibercultura aproximações e distanciamentos de conceitos e práticas na contemporaneidade. Periferia, Educação, Cultura \& Comunicação. v. 4 n. 2 jul-dez 2012 e v. 5 n. 1 jan-jun 2013.

GIGLIO, Kamil. Comunicação, Educação e Tecnologia: espaços colaborativos digitais de ensino e aprendizagem. Revista Intersaberes. v.12 n.26. mai. ago, 2017 
GUILHERME, A., GIRAFFA, L. M. M., MARTINS, C. Contra-educação e cibercultura: uma interlocução possível à luz da cidadania global. Foro de Educación, 16(24), 41-56, 2018. JUNIOR, Gilson Cruz. Entre filhos e órfãos da Cibercultura: revisitando a noção de nativos digitais. Revista Observatório. Palmas, v.4, n. 1, p. 837-858, jan-mar. 2018. DOI: http://dx.doi.org/10.20873/uft.2447.

LARAIA, Roque de Barros. Cultura: um conceito antropológico. 21. ed. Rio de Janeiro: Jorge Zahar, 2007.

LEMOS, André. Cibercultura: tecnologia e vida social na cultura contemporânea. Porto Alegre: Sulina, 2008.

LEVY, Pierre. Cibercultura. São Paulo: Editora 34 Ltda., 1999.

LÉVY, Pierre.Cibercultura. São Paulo: Editora 34, 2009.

LEVY, Pierre. A conexão planetária. São Paulo: Editora 34 Ltda., 2001.

LIMA, Caroline Costa Nunes; CARVALHO, Felipe Silva Ponte; JÚNIOR, Dilton Ribeiro Couto. Linguagem emocional na prática docente online: implicações educacionais cotidianas. Rev. Inter. Educ. Sup. Campinas, SP. v.4. n.3 p.542-557 set./dez. 2018.

MACIELL, Katy da Costa; BRUM, Paula Fernanda Rodrigues; GRITTI, Maria Silvana. Os desafios da Educação no Campo em tempos de Cibercultura. RELACult - Revista Latinoamericana de Estudos em Cultura e Sociedade. v. 05, ed. especial, abr., 2019, artigo no 1276.

MALAGGI, Vitor. A utilização da informática na educação: um olhar através da cibercultura e do pensamento pós-moderno. Revista Espaço Acadêmico. n. 134. Jul. 2012. Mensal.

MALAGGI, Vitor; MARCON, Karina. Cibercultura e Educação: algumas reflexões sobre processos educativos na sociedade tecnológica contemporânea. Revista Espaço Acadêmico. n. 132. Mai.2012.

MILL, Daniel. Flexibilidade educacional na cibercultura: analisando espaços, tempos e currículo em produções científicas da área educacional. RIED. v. 17: 2, 2014, p. 97-126.

OLIVEIRA, Kaio Eduardo de Jesus; PORTO, Cristiane de Magalhães; ALVES André Luiz. Memes de redes sociais digitais enquanto objetos de aprendizagem na Cibercultura: da viralização à educação. Acta Sci. Educ., v. 41, e42469, 2019.

PAZ. T.S; SALES, C.B.O; SANTOS, N.R; JUNQUEIRA, E.S. Processos formativos de uma mídia ninja e as novas narrativas do ativismo no contexto da cibercultura. HOLOS, Ano 32, v. 4, 2016.

PRIMO, Alex Teixeira; VALIATI, Vanessa; LUPINACCI, Ludmila; BARROS, Laura. Conversações fluidas na cibercultura. Revista Famecos - mídia, cultura e tecnologia. Porto Alegre. v. 24, n. 1, jan., fev. mar. abr. 2017.

REBOUÇAS, Davi de Menezes; INOCÊNCIO, Luana Ellen de Sales; SANTOS, Letícia Adriana Ferreira Pires dos. Interatividade, m-learning e apropriações das mídias digitais para a inovação da educação superior. Revista Educação e Cultura Contemporânea. Rio de Janeiro, v. 16, n. 44, 2019. Http://DX.DOI.ORG/10.5935/2238-1279.20190068

RIBEIRO, Mayra Rodrigues Fernandes; SANTOS, Edméa Oliveira dos. Ciberautorcidadão: contribuição para pensar e fazer a formação docente e discente na cibercultura. Revista e- 
Curriculum. São Paulo. v.16, n.2, p. 565 - 597 abr./jun.2018. http://revistas.pucsp.br/index.php/curriculum. Acesso em: 24 de jan. 2020.

SAMPAIO, R. F.; MANCINI, M. C. Estudos de Revisão Sistemática: um guia para síntese criteriosa da evidência científica. V. 11, n. 1. São Carlos-SP: Revista Brasileira de Fisioterapia, p. 83-89, 2007.

SANTOS, Edméa Oliveira; CARVALHO, Felipe Silva Pontes; PIMENTEL, Mariano. Mediação docente online para colaboração: notas de uma pesquisa-formação na cibercultura. ETD - Educ. Temat. Digit. Campinas/SP. v.18 n.2 p. 23-42 jan.abr.2016.

SANTOS, Edméa; WEBER, Aline. Educação e cibercultura: aprendizagem ubíqua no currículo da disciplina Didática. Rev. Diálogo Educ. v. 13, n. 38, p. 285-303, jan./abr. 2013.

SANTOS, Edméa; MARTINS, Vivian. Cibervídeos e Multiletramentos na Educação Online. Revista Observatório. Palmas. v. 4, n. 5, p. 231-262, ago. 2018.

SANTOS, Gustavo Souza; FREITAS, Ronilson Ferreira; REIS, Vivianne Margareth Chaves Pereira; ROCHA, Josiane Santos Brant. Educação como terreno de epifania da cibercultura: leituras e cenários. Revista Multitexto, v. 3, n. 01, 2015.

SILVA, Lebiam Tamar Gomes; BEZERRA, Irinalda da Silva. Hibridações da cultura acadêmica com a cibercultura: análise das práticas acadêmicas no ambiente virtual de aprendizagem moodle. Educação em Revista. Belo Horizonte. v.34, 2018.

SOFFNER, Renato Kraide; KIRSCH, Deise Becker. Educação na cibercultura: as tecnologias da inteligência e a práxis educativa. Revista Intersaberes. v. 9, n. 18, p. 220 - 228. jul. - dez. 2014.

TEIXEIRA, Adriano Canabarro. A educação em um contexto de cibercultura. Revista Espaço Acadêmico. n. 138. Dez. 2012.

THOMPSON, Jonh B. Ideologia e cultura moderna. Petrópolis/RJ: Brasiliense, 1995.

VELOSO, Maristela Midlej Silva de Araújo; BONILLA, Maria Helena Silveira. O professor e a autoria em tempos de cibercultura: a rede da criação dos atos de currículo. Revista Brasileira de Educação. Campinas/SP, v. 23 e230026, 2018. DOI: 10.1590/S141324782018230026.

\section{Informações do(a)(s) autor(a)(es)}

Sandra Cristina Morais de Souza Afiliação institucional: UFPB

E-mail: profsandrapsico@gmail.com

ORCID: http://orcid.com//0000-0002-4176-4352

Link Lattes: http://lattes.cnpq.br/7789325320201609 